\title{
Age- and sex-matched comparison of diet quality in patients with heart failure to similarly aged healthy older adults
}

\author{
JungHee $\mathrm{Kang}^{1}{ }^{*}$ (D), Debra K. Moser ${ }^{1}$, Martha J. Biddle ${ }^{1}$, GYeon $\mathrm{Oh}^{2}$ and Terry A. Lennie ${ }^{3}$ \\ ${ }^{1}$ College of Nursing, University of Kentucky, 2201 Regency Rd. Suite 403, Lexington, KY 40503, USA \\ ${ }^{2}$ Department of Pharmacy Practice and Science, College of Pharmacy, University of Kentucky, 789 South Limestone Street, Lexington, \\ KY 40536, USA \\ ${ }^{3}$ College of Nursing, University of Kentucky, 751 Rose Street, Lexington, KY 40536, USA
}

(Received 24 January 2021 - Final revision received 12 June 2021 - Accepted 16 July 2021)

Journal of Nutritional Science (2021), vol. 10, e65, page 1 of 9

doi:10.1017/jns.2021.51

Abstract

The aims of this study were to (1) compare diet quality between patients with heart failure (HF) and age- and sex-matched community-dwelling healthy older adults and (2) determine whether having HF was associated with a lower Healthy Eating Index-2015 (HEI-2015) score and risk of micronutrient deficiency. The HEI-2015 and macro- and micronutrient intakes of patients with HF were compared with healthy older adults (N 102; 55-92 years old; $53 \%$ female). A paired $t$-test or Wilcoxon singed-rank test, McNemar's test, and conditional logistic regression were used to assess the association between diet quality and HF status. Median values for HEI-2015 and the number of micronutrient deficiency were used to dichotomise into groups in the conditional logistic regression. There was no significant between-group difference in the HEI-2015 total score (P 0.059), whereas the whole grain component was lower in patients with HF than in healthy older adults $(3.1 \pm 3.5 v .4 .5 \pm 3 \cdot 1, P 0 \cdot 037$; respectively). Total caloric intake was lower in patients with HF than in healthy older adults $(1683 \pm 595 v .2104 \pm 670 \mathrm{kcal} ; P<0 \cdot 001)$. Patients with HF had a higher average number of micronutrient deficiencies than healthy older adults $(4[2,6] \nu .1[0,4]$, respectively, $P<0 \cdot 001)$. Patients with HF had four times higher odds of being in a high micronutrient deficiency group than healthy older adults, controlling for socio-demographics and body mass index (adjusted odds ratio [ $95 \%$ confidence interval]: $4 \cdot 04[1 \cdot 06,15 \cdot 41])$. Our findings demonstrate that diet quality measured by nutritional intake identifies patients with HF with lower caloric intake and higher micronutrient deficiencies compared with age- and sex-matched healthy older adults.

Key words: Diet quality: Heart failure: Healthy eating index: Micronutrient deficiency: Older adults

\section{Introduction}

Heart failure $(\mathrm{HF})$ is a growing epidemic that affected approximately 6.2 million individuals in the United States between 2013 and $2016^{(1)}$. The annual incidence of $\mathrm{HF}$ is 915000 , and the prevalence in adults is projected to increase by $46 \%$ from 2012 to 2030 due to aging of the population ${ }^{(2,3)}$. Although major advances in medical management of $\mathrm{HF}$ have decreased symptom burden and improved outcomes, patients remain at risk for frequent rehospitalisations and death after optimisation of medical treatment ${ }^{(4)}$. Nutrition is among the non-pharmacologic factors that can complement medical treatment to improve $\mathrm{HF}$ outcomes ${ }^{(5)}$. However, most patients with HF need improvement in their diet quality $^{(6)}$. We previously demonstrated that patients with $\mathrm{HF}$ who had higher number of dietary micronutrient deficiencies had double the risk of hospitalisation or death compared with those who had lower number of micronutrient deficiencies $^{(7)}$. Most patients with HF are older, and older age is associated with consuming lower quality diet ${ }^{(8)}$. It is not known whether lower diet quality in patients with HF is primarily a

Abbreviations: HF: heart failure; HEI-2015: Healthy Eating Index-2015; BMI: body mass index; NDSR: Nutrition Data System for Research software

* Corresponding author: JungHee Kang, fax: +1 859323 1057, email junghee.kang@uky.edu 
function of older age or HF. To answer this question, we (1) compared diet quality (measured as Healthy Eating Index (HEI)-2015, dietary macronutrient and micronutrient intakes, and number of micronutrient deficiencies) between community-dwelling older patients with HF and age- and sexmatched healthy older adults, and (2) determined whether HF status was associated with lower HEI-2015 or higher risk of having dietary micronutrient deficiencies.

\section{Methods}

\section{Study design}

We used a cross-sectional design to compare data collected from an observational study of diet quality in communitydwelling patients with HF and healthy older adults. The parent study for the HF group was a longitudinal multicenter study examining nutrition, body mass index (BMI), and cardiac event-free survival in patients with HF. The parent study for the comparative group (healthy older adult) was a crosssectional study designed to collect nutritional status, psychological, behavioural, and physical variables in a group of healthy community-dwelling older adults to compare patients with HF. These two groups were age- and sex-matched using a Statistical Analysis System Macro for one-to-one matching between patients with $\mathrm{HF}$ and healthy older adults and based on participants' age (allowing \pm 1 year) and sex to reduce confounding ${ }^{(9)}$. This study was conducted according to the Declaration of Helsinki guidelines, and all procedures involving research study participants were approved by the University of Kentucky Institutional Review Boards. The study was thoroughly explained to all participants who then signed the written consent form.

\section{Sample}

Participants with HF were recruited from midwestern and southeastern HF clinics and health older adults from a senior citizen centre. Patients with HF were eligible to participate in this study if they had (1) documented diagnosis of HF, (2) been stable on cardiac medications for at least 3 months, (3) no history of myocardial infarction or stroke within 3 months of enrolment and (4) no terminal or inflammatory comorbidity. Healthy older adults were eligible if they (1) were age $\geq 55$ years, (2) had no obvious cognitive deficit as evidenced during conversation with the researcher and (3) had no history of myocardial infarction, coronary artery bypass surgery, angioplasty, HF, cancer, liver disease, gastrointestinal disease or endstage renal disease. Participants were enrolled between May 2005 and March 2010.

\section{Measurements}

Demographic variables and BMI. Age, sex, ethnicity, marital status, and financial status were collected via a self-reported questionnaire. For patients with HF, their status was confirmed from medical record review, as were the presence of comorbidities. Weight and height were obtained from all participants by research nurses in the clinical research centre. BMI was calculated as body weight in kilograms divided by height in metres squared.

Diet quality. Using 4-day food diaries (analysed using The Nutrition Data System for Research software [NDSR; Minneapolis, MN]), participants were asked to record all foods and liquids consumed for 1 weekend day and 3 weekdays. A trained research assistant visited participants' homes to provide digital food scales with detailed oral and written instructions to weigh and record each food item consumed. Participants also received food models to estimate serving sizes in case they ate at a place (e.g., a restaurant) where they could not weigh their food. Participants were asked to provide a return demonstration of food measurement and recording in their food diary to ensure the accuracy of 4-day food diaries. On the first day of the food diary collection, a research assistant called participants to review the procedure and answer any questions they had. Participants' 4-day food diaries were reviewed with participant the morning after completion by a registered dietitian for the verification of serving sizes, food preparation methods, and to collect any missing data. The following two indicators of diet quality were derived from the 4-day food diaries: (1) the HEI-2015 and (2) macro- and micronutrient intakes, and number of dietary micronutrient deficiencies.

Healthy Eating Index-2015. The HEI assess whether foods consumed align with the Dietary Guidelines for Americans (DGA) ${ }^{(10)}$. The HEI-2015 ${ }^{(11)}$ version of the HEI reflects the 2015-2020 DGA. The HEI is composed of scores for thirteen dietary components. Nine 'adequacy' components are those recommended to consume by the United States Department of Agriculture: total fruits (five points), whole fruits (five points), total vegetables (five points), greens and beans (five points), whole grains (ten points), dairy (ten points), total protein foods (five points), seafood and plant proteins (five points), and fatty acid ratio (ten points). Four 'moderation' components are those recommended for consumption in limited amounts are scored in reverse with lower consumption associated with higher scores: refined grains (ten points), sodium (ten points), saturated fats (ten points), and added sugars (ten points). The total HEI-2015 score is the sum of thirteen component scores and can range from 0 to 100 . Higher scores indicate closer reflects closer conformance with dietary guidance, and thus, better diet quality.

The HEI-2015 is calculated based on a $1000 \mathrm{kcal} / \mathrm{d}$ formula to characterise diet quality while controlling for diet quantity and addresses the consumption of energy-dense and nutrientpoor food and ingredients. The NDSR software, developed by the Nutrition Coordination Center (NCC), was used to analyse 4-day food diary data and create variables needed to calculate scores for each component of the HEI-2015 ${ }^{(12)}$. Briefly, average daily intake of each food subgroup was calculated from the NDSR output data ${ }^{(13)}$. Total servings were adjusted (i.e. cups, ounces, grams, or \% energy) according to the Nutrition 
Coordinating Center Food Serving Count System. The adjusted servings were divided by energy intake to generate servings of HEI-2015 components per $1000 \mathrm{kcal}$. The final scores of each component were generated linearly based on the standards for maximum and minimum scores ${ }^{(14)}$. Validity and reliability of the HEI-2015 were demonstrated using $24 \mathrm{~h}$ recalls from the National Health and Nutrition Examination Survey 2011-2012 conducted by the Centers for Disease Control and Prevention and National Center for Health Statistics ${ }^{(15)}$. Reedy et al. reported that HEI-2015 scores were at or very near the maximum levels for most sets of exemplary menus.

\section{Macro- and micronutrient diet quality}

Macronutrient distribution. Intake of carbohydrate, protein, and fat by grams and as percentage of total kcal were obtained from the NDSR output ${ }^{(16)}$.

Micronutrient intake. Four-day averaged dietary intake of micronutrients was obtained from the NDSR output. The number of eleven vitamins (thiamin, riboflavin, niacin, pantothenic acid, vitamin $\mathrm{B}_{6}$, folate, vitamin $\mathrm{B}_{12}$, vitamin $\mathrm{C}$, vitamin $\mathrm{D}$, vitamin $\mathrm{E}$ and vitamin $\mathrm{K}$ ) and six minerals (calcium, magnesium, selenium, iron, zinc and phosphorus) defined as deficient in the diet were compared between healthy older adults and patients with $\mathrm{HF}^{(7)}$. Micronutrient intake was also calculated based on $1000 \mathrm{kcal} / \mathrm{d}$ for the qualitative comparison. Dietary deficiency of thiamin, riboflavin, niacin, vitamin $\mathrm{B}_{6}$, folate, magnesium and phosphorus was determined using the probability formula recommended by the National Academy of Medicine ${ }^{(17-19)}$. A probability score of less than -1 indicated that, based on the 4-day averaged intake, there was a high probability the individual's diet was habitually deficient in that nutrient. Because probability formulas could not be used due to insufficient population data, dietary deficiency of calcium, iron, selenium, zinc, vitamin $B_{12}$, vitamin $C$, vitamin $D$ and vitamin $\mathrm{E}$ was determined by dividing average intake by estimated average requirement. Deficiency was defined as a ratio less than 1.0. Pantothenic acid and vitamin $K$ deficiency were defined as average intake $<50 \%$ of the adequate intake value for each nutrient, because estimated average requirement values were not available for these two micronutrients. The number of micronutrients defined as deficient was totalled to determine nutrient diet quality.

\section{Data analysis}

We used SAS software for data analyses (version 9.4). Ageand sex-matched data between healthy older adults and patients with HF were horizontally combined to compare sample characteristics, HEI-2015 scores, average intake of macronutrients, average intake of micronutrients and the proportions of micronutrient deficiencies between healthy older adults and patients with HF. Because age- and sex-matched groups are no longer considered independent, a McNemar's test or an Exact test for symmetry was used to compare categorical variables between the two groups. The Shapiro-Wilk test was used to test the normality of continuous variables. A paired sample $t$-test was used for the variables when the mean difference between healthy older adults and patients with HF was normally distributed, while the Wilcoxon signed-rank test was applied when the mean difference between healthy older adults and patients with HF did not meet the normal distribution assumption. For the logistic regression, age- and sex-matched data between healthy older adults and patients with HF were vertically combined. Conditional logistic regression was used to examine the relationship between HF $v$. healthy status and diet quality defined by HEI-2015 scores and dietary micronutrient deficiencies, respectively. As a response variable, HEI-2015 scores were categorised into two groups at the median value: higher quality diet group (higher HEI-2015 score) and lower quality diet group (lower HEI-2015 score). To use the number of dietary micronutrient deficiency as a response variable, we created a binary variable using a cut-off point 2 as the high micronutrient deficiency group. Participants with zero to one micronutrient deficiency were classified as the low deficiency group. Marital status, BMI, financial status, and living arrangements were used as covariates in adjusted conditional regression models. Statistical significance was set at $P<0 \cdot 05$; all tests were two-sided.

\section{Results}

\section{Sample characteristics}

The mean age of participants was $69.9 \pm 8.6$ (range: 55-92) years old and $53 \%$ were female. Comparisons of participant characteristics between the two groups are shown in Table 1. McNemar's test and an Exact test for symmetry indicated that there was a lower proportion of married/cohabitating and a higher proportion of "not enough to make ends meet" in patients with HF compared with age- and sexmatched healthy older adults $(P 0.025$ and $P<0.001$, respectively). Patients with HF had a higher average BMI than healthy older adults $\left(29 \cdot 2 \pm 6.8 v .26 \cdot 4 \pm 4.6 \mathrm{~kg} / \mathrm{m}^{2} ; P 0 \cdot 018\right)$. There was a higher proportion of hypertension and diabetes mellitus in patients with HF compared with healthy older adults $(P<$ $0 \cdot 001)$.

\section{Diet quality by HEl-2015 scores}

As shown in Table 2, there was no statistically significant difference in total HEI-2015 scores between patients with $\mathrm{HF}$ and healthy older adults $(54.9 \pm 11.7 v .59 \cdot 79 \pm 12 \cdot 6$, respectively, $P$ 0.059). There were no differences in adequacy components between patients with $\mathrm{HF}$ and healthy older adults, except the intake of whole grains was significantly lower in patients with $\mathrm{HF}$ than in healthy older adults $(3 \cdot 1 \pm 3 \cdot 5 v$. $4 \cdot 5 \pm 3 \cdot 1$, respectively, $P 0 \cdot 037)$. None of the moderation components or total HEI-2015 scores was different between patients with $\mathrm{HF}$ and healthy older adults.

\section{Macronutrient composition of diet}

Patients with HF had a lower total caloric intake (1683 $\pm 595 v$. $2104 \pm 670 \mathrm{kcal} ; \quad P<0 \cdot 001)$ than healthy older adults 
Table 1. Participant characteristics (N 102)

\begin{tabular}{|c|c|c|c|c|}
\hline \multirow{2}{*}{ Characteristics } & \multirow[b]{2}{*}{ Total $(N 102)^{\dagger}$} & \multicolumn{2}{|c|}{ Mean [SD] or $n(\%)$} & \multirow[b]{2}{*}{$P$-value } \\
\hline & & Healthy adults ( $n$ 51) & Heart failure $(n 51)$ & \\
\hline Sex (female) & $54(53)$ & $27(53)$ & $27(53)$ & \\
\hline Age (years) ${ }^{f}$ & $69.9[8 \cdot 6]$ & $69 \cdot 8[8 \cdot 6]$ & $69.9[8 \cdot 6]$ & 0.806 \\
\hline Ethnicity (Caucasian) $^{\S}$ & $90(88)$ & $46(90)$ & $44(86)$ & 0.564 \\
\hline Marital status (married/cohabitating) ${ }^{\S}$ & $61(61)$ & $35(71)$ & $25(51)$ & 0.025 \\
\hline \multicolumn{5}{|l|}{ Financial status ${ }^{\S}$} \\
\hline Comfortable & $56(54.9)$ & $38(74.5)$ & $18(35 \cdot 3)$ & $<0.001$ \\
\hline Enough to make ends meet & $35(34 \cdot 3)$ & $12(23.5)$ & $23(45 \cdot 1)$ & \\
\hline Not enough to make ends meet & $11(10 \cdot 8)$ & $1(2 \cdot 0)$ & $10(19 \cdot 6)$ & \\
\hline $\operatorname{BMl}\left(\mathrm{kg} / \mathrm{m}^{2}\right)^{\ddagger}$ & $27 \cdot 8[6 \cdot 0]$ & $26 \cdot 4[4 \cdot 6]$ & $29 \cdot 2[6 \cdot 8]$ & 0.018 \\
\hline Hypertension (yes) $)^{\S}$ & $54(54.5)$ & $14(28)$ & $40(78)$ & $<0.001$ \\
\hline Diabetes mellitus (yes) $)^{\S}$ & $27(27)$ & $5(10)$ & $22(43)$ & $<0.001$ \\
\hline
\end{tabular}

SD, standard deviation.

† Sample size may be less for some variables due to missing data

${ }^{\ddagger}$ Paired $t$-test was used.

$\S$ The McNemar's test or an Exact test for symmetry was used.

(Table 3). Patients with HF also had lower carbohydrate (195 $\pm 71 v .256 \pm 91 \mathrm{~g}, P<0.001)$, protein $(68 \pm 23 v .81 \pm 20 \mathrm{~g}, P$ $0.035)$ and fat intakes $(71 \pm 34 v .86 \pm 37 \mathrm{~g}, P 0 \cdot 038) \mathrm{com}-$ pared with healthy older adults. The caloric intakes of animal and vegetable protein subcomponents and unsaturated fat subcomponents were also lower in patients with HF. However, there were no significant differences in percent of food energy from carbohydrate, protein and fat between patients with HF and healthy older adults.

\section{Micronutrient composition}

Average daily intakes of calcium, magnesium, vitamin $\mathrm{D}$, vitamin $\mathrm{C}$, vitamin $\mathrm{K}$, folate, pantothenic acid, vitamin $\mathrm{B}_{6}$, selenium, phosphorus, niacin, thiamin and riboflavin were lower in patients with HF compared with healthy older adults (Table 4). The proportion of participants with diets deficient in calcium (73 v. $49 \%$ ), magnesium (73 v. $28 \%$ ), vitamin $\mathrm{D}(73 v .45 \%)$, vitamin $\mathrm{C}(39 v .18 \%)$ and folate $(35 v .16 \%)$ was higher in patients with $\mathrm{HF}$ compared with healthy older adults
$(P 0.019, P<0.001, P 0 \cdot 011, P 0.022$ and $P 0.025$, respectively). Patients with $\mathrm{HF}$ had a higher average number of micronutrient deficiencies compared with healthy older adults $(4[2,6] v .1[0,4]$, respectively, $P<0 \cdot 001)$. When we adjusted micronutrient intake per $1000 \mathrm{kcal} / \mathrm{d}$, magnesium (174 [159, 192] v. 152 [140, 165], $P$ 0.037) and vitamin $C$ (74.8 [56.6, 98.7] v. $48.6[35.4,66.6], P 0.049)$ were still significantly lower in patients with HF compared with healthy older adults (Table 5).

\section{Association of HF status and diet quality}

In the conditional logistic regression model, we regressed diet quality on HF status using total HEI-2015 scores (cut-off point: median value $57 \cdot 6$ ) and the status of micronutrient ( $\leq 1 \quad v .>1)$ deficiencies while controlling for marital status, BMI, financial status and living arrangements in age- and sexmatched community-dwelling older adults (Table 6). There was no significant association between $\mathrm{HF}$ status and HEI-2015 in either the unadjusted or adjusted model

Table 2. HEl-2015 scores between age- and sex-matched healthy older adults and patients with heart failure $(N 102)$

\begin{tabular}{|c|c|c|c|c|c|}
\hline \multirow[b]{2}{*}{ HEI-2015 components } & \multicolumn{2}{|c|}{ Healthy adults ( $n 51$ ) } & \multicolumn{2}{|c|}{ Heart failure ( $n 51)$} & \multirow[b]{2}{*}{$P$-value } \\
\hline & Mean or (median) & SD or [Q1, Q3] & Mean or (median) & sD or [Q1, Q3] & \\
\hline Total HEl-2015 ${ }^{\dagger}$ & $59 \cdot 79$ & $12 \cdot 6$ & 54.9 & $11 \cdot 7$ & 0.059 \\
\hline Total fruits (cups) ${ }^{\dagger}$ & $2 \cdot 7$ & 1.7 & $2 \cdot 3$ & 1.9 & 0.240 \\
\hline Whole fruits (cups) ${ }^{\dagger}$ & $3 \cdot 2$ & $1 \cdot 6$ & $2 \cdot 6$ & $2 \cdot 0$ & 0.095 \\
\hline Total vegetables (cups) ${ }^{\dagger}$ & $3 \cdot 8$ & $1 \cdot 1$ & 3.5 & 1.5 & 0.264 \\
\hline Greens and beans (cups) ${ }^{\dagger}$ & 3.4 & $1 \cdot 8$ & $2 \cdot 8$ & $2 \cdot 0$ & 0.148 \\
\hline Whole grains $(o z)^{\dagger}$ & 4.5 & $3 \cdot 1$ & $3 \cdot 1$ & 3.5 & 0.037 \\
\hline Dairy (cups) ${ }^{\dagger}$ & $5 \cdot 8$ & $2 \cdot 3$ & $5 \cdot 6$ & $3 \cdot 4$ & 0.715 \\
\hline Total protein $(\mathrm{oz})^{\ddagger}$ & $(5 \cdot 0)$ & {$[5 \cdot 0,5 \cdot 0]$} & $(5 \cdot 0)$ & {$[4 \cdot 8,5 \cdot 0]$} & 0.814 \\
\hline Seafood and plant proteins $(\mathrm{oz})^{\ddagger}$ & $(5 \cdot 0)$ & {$[2 \cdot 4,5 \cdot 0]$} & $(4 \cdot 6)$ & {$[1 \cdot 8,5 \cdot 0]$} & 0.603 \\
\hline Fatty acid ratio & 4.7 & 3.3 & $4 \cdot 7$ & $3 \cdot 1$ & 0.913 \\
\hline Refined grains $(\mathrm{oz})^{\dagger}$ & $7 \cdot 4$ & $3 \cdot 1$ & $6 \cdot 9$ & 2.7 & 0.456 \\
\hline Sodium $(g)^{\dagger}$ & $4 \cdot 0$ & 2.9 & 3.4 & $3 \cdot 1$ & 0.364 \\
\hline Added sugars (\% energy) ${ }^{\dagger}$ & $6 \cdot 6$ & $2 \cdot 8$ & 6.9 & $3 \cdot 2$ & 0.548 \\
\hline Saturated fat $(\% \text { energy })^{\dagger}$ & $5 \cdot 3$ & 3.4 & 4.8 & 3.0 & 0.393 \\
\hline
\end{tabular}

HEI, Healthy Eating Index-2015; SD, standard deviation; Q1, the first quartile; Q3, the third quartile; oz, ounce.

${ }^{\dagger}$ Determined using paired $t$-tests.

‡ Determined using Wilcoxon signed-rank tests. 
Table 3. Comparison of macronutrients between age- and sex-matched healthy older adults and patients with heart failure $(N 102)$

\begin{tabular}{|c|c|c|c|c|c|}
\hline \multirow[b]{2}{*}{ Variables } & \multicolumn{2}{|c|}{ Healthy Adults $(n=51)$} & \multicolumn{2}{|c|}{ Heart Failure $(n=51)$} & \multirow[b]{2}{*}{$P$-value } \\
\hline & Mean or Median & SD or (Q1, Q3) & Mean or Median & SD or (Q1, Q3) & \\
\hline \multicolumn{6}{|c|}{ Absolute values of macronutrients } \\
\hline Total energy intake $(\mathrm{kcal})^{\dagger}$ & 2,104 & 670 & 1,683 & 595 & $<\cdot 001$ \\
\hline Carbohydrate $(\mathrm{g})^{\dagger}$ & $255 \cdot 7$ & $90 \cdot 5$ & $195 \cdot 3$ & $71 \cdot 1$ & $<\cdot 001$ \\
\hline Protein $(g)^{\dagger}$ & $80 \cdot 6$ & $19 \cdot 84$ & $68 \cdot 12$ & 23.04 & .0035 \\
\hline Animal protein $(\mathrm{g})^{\ddagger}$ & 50 & $(43,62)$ & 45 & $(33,61)$ & $<\cdot 001$ \\
\hline Vegetable protein $(\mathrm{g})^{\ddagger}$ & 25 & $(20,32)$ & 21 & $(15,24)$ & $<\cdot 001$ \\
\hline Fat $(\mathrm{g})^{\dagger}$ & $86 \cdot 2$ & 37 & 71.5 & 33.9 & 0.038 \\
\hline Saturated fat $(\mathrm{g})^{\ddagger}$ & 25 & $(20,33)$ & 21 & $(15,29)$ & $<\cdot 001$ \\
\hline Monosaturated fat $(\mathrm{g})^{\ddagger}$ & 30 & $(23,41)$ & 23 & $(18,35)$ & $<\cdot 001$ \\
\hline Polysaturated fat $(\mathrm{g})^{\ddagger}$ & 15 & $(11,21)$ & 12 & $(10,18)$ & $<\cdot 001$ \\
\hline \multicolumn{6}{|c|}{ Percent (\%) of food energy } \\
\hline Carbohydrate $^{\dagger}$ & $49 \cdot 3$ & 7.4 & $47 \cdot 1$ & 7.5 & 0.120 \\
\hline Protein $^{\dagger}$ & $16 \cdot 2$ & $3 \cdot 6$ & $16 \cdot 8$ & 3.4 & 0.350 \\
\hline Animal protein $(\mathrm{g})^{\ddagger}$ & $10 \cdot 6$ & 3.4 & 11.4 & 3.5 & 0.223 \\
\hline Vegetable protein $(\mathrm{g})^{\ddagger}$ & 5.3 & $(4 \cdot 1,6 \cdot 3)$ & 4.9 & $(4 \cdot 1,5 \cdot 8)$ & 0.135 \\
\hline $\mathrm{Fat}^{\dagger}$ & $35 \cdot 5$ & 6.4 & $36 \cdot 7$ & $6 \cdot 8$ & 0.330 \\
\hline Saturated fat ${ }^{\ddagger}$ & $11 \cdot 1$ & $(9.5,14.6)$ & $12 \cdot 3$ & $(10 \cdot 4,13 \cdot 9)$ & 0.381 \\
\hline Monosaturated fat $^{\dagger}$ & $13 \cdot 7$ & 3.2 & $14 \cdot 1$ & 3.5 & 0.454 \\
\hline Polysaturated fat ${ }^{\dagger}$ & $7 \cdot 3$ & $2 \cdot 2$ & 7.4 & $2 \cdot 1$ & 0.760 \\
\hline
\end{tabular}

SD, standard deviation; Q1, the first quartile; Q3, the third quartile.

${ }^{\dagger}$ Determined using paired $t$-tests.

${ }^{\ddagger}$ Determined using Wilcoxon signed-rank tests.

(P 0.079 or $P 0 \cdot 751$, respectively). However, the model indicated a statistically significant association between HF status and dietary micronutrient deficiency in both unadjusted (bivariate) and adjusted (controlling for marital status, BMI, financial status and living arrangements) models ( $P$ 0.004 and $P 0 \cdot 041$, respectively). In the unadjusted model, the estimated odds of patients with HF being in the high micronutrient deficiency group was 3.4 times higher than similarly aged healthy older adults (95\% confidence interval [1.48, 7.96]). While holding covariates constant, the estimated odds

Table 4. Summary of the micronutrients, including geometric means and their corresponding $95 \%$ confidence intervals and percentage of the deficiency between age- and sex-matched healthy adults and patients with heart failure groups (N 102)

\begin{tabular}{|c|c|c|c|c|c|c|}
\hline \multirow[b]{2}{*}{ Variable } & \multicolumn{2}{|c|}{ Geomean (95 \% Cl) } & \multirow[b]{2}{*}{$P$-value } & \multicolumn{2}{|c|}{$\%$ Deficient $^{\dagger}$} & \multirow[b]{2}{*}{$P$-value ${ }^{\ddagger}$} \\
\hline & Healthy (n 51) & $\mathrm{HF}(n 51)$ & & Healthy & HF & \\
\hline Calcium ${ }^{\S}$ & $1064(943,1201)$ & $730(619,861)$ & $<0.001^{\| 1}$ & $49 \cdot 0$ & $72 \cdot 6$ & 0.019 \\
\hline Magnesium & $351(317,390)$ & $242(214,274)$ & $<0.001^{\|}$ & $27 \cdot 5$ & $72 \cdot 6$ & $<0.001$ \\
\hline Vitamin $D^{\S}$ & $8.6(6.6,11 \cdot 2)$ & $5(3.9,6 \cdot 6)$ & $0.011^{\|}$ & $45 \cdot 1$ & $72 \cdot 6$ & 0.011 \\
\hline Vitamin $\mathrm{E}^{\S}$ & $19 \cdot 1(13 \cdot 2,27 \cdot 7)$ & $13(8 \cdot 6,19 \cdot 4)$ & $0.203^{\|}$ & $43 \cdot 1$ & 58.8 & 0.131 \\
\hline Zinc ${ }^{\S}$ & $13.9(11 \cdot 8,16 \cdot 3)$ & $11.6(9.5,14.2)$ & $0.164^{\|}$ & $33 \cdot 3$ & $51 \cdot 0$ & 0.061 \\
\hline Vitamin $C^{\S}$ & $150.6(113.6,199.6)$ & $77 \cdot 2(54 \cdot 6,109 \cdot 2)$ & $0.004^{\|}$ & $17 \cdot 7$ & $39 \cdot 2$ & 0.022 \\
\hline Vitamin $\mathrm{K}^{* *}$ & $105.1(89.2,123.9)$ & $75.8(61.2,93.9)$ & $0.016^{\|}$ & $35 \cdot 3$ & $51 \cdot 0$ & 0.103 \\
\hline Folate & $680(477,968)$ & $416(351,493)$ & $0.001^{\dagger \dagger}$ & $15 \cdot 7$ & $35 \cdot 3$ & 0.025 \\
\hline Vitamin $\mathrm{B}_{12} \S$ & $12 \cdot 2(6 \cdot 4,23 \cdot 2)$ & $7 \cdot 1(4 \cdot 1,12 \cdot 3)$ & $0.073^{t \dagger}$ & $3 \cdot 9$ & $16 \cdot 0$ & 0.058 \\
\hline Pantothenic acid ${ }^{\star \star}$ & $9.5(7.7,11.8)$ & $6 \cdot 2(5 \cdot 2,7 \cdot 4)$ & $0.002^{\| 1}$ & $17 \cdot 7$ & $25 \cdot 5$ & 0.285 \\
\hline Vitamin $\mathrm{B}_{6}{ }^{\pi}$ & $3.2(2.5,4)$ & $2(1 \cdot 6,2 \cdot 3)$ & $<0.001^{\| 1}$ & 2 & $7 \cdot 8$ & 0.375 \\
\hline Selenium ${ }^{\S}$ & $157 \cdot 8(100 \cdot 5,247 \cdot 8)$ & $91.5(79.9,104.9)$ & $0.002^{\dagger \dagger}$ & 0 & $7 \cdot 8$ & - \\
\hline Iron $\S$ & $17 \cdot 2(15,19 \cdot 6)$ & $15 \cdot 2(12.4,18.5)$ & $0.232^{\|}$ & 0 & 3.9 & - \\
\hline Phosphorus" & $1324(1228,1427)$ & $1043(937,1162)$ & $<0.001^{\|}$ & 0 & $5 \cdot 9$ & - \\
\hline Niacin" & $36.1(28.7,45.4)$ & $23.4(19.4,28.2)$ & $0.001^{t \dagger}$ & 0 & $5 \cdot 9$ & - \\
\hline Thiamin & $2 \cdot 5(2,3)$ & $1.7(1.5,1.9)$ & $<0.001^{\dagger \dagger}$ & 0 & $2 \cdot 0$ & - \\
\hline Riboflavin & $3.2(2 \cdot 7,3 \cdot 9)$ & $2 \cdot 3(2,2 \cdot 6)$ & $0.005^{\dagger \dagger}$ & 0 & 0 & - \\
\hline
\end{tabular}

$\mathrm{Cl}$, confidence interval; $\mathrm{HF}$, heart failure.

Dietary micronutrient intakes were calculated as 4-day average.

Geomean was calculated as the result of back transformation of the mean of the logarithms of dietary micronutrient intakes.

For calcium, magnesium, vitamin $\mathrm{E}$, zinc, vitamin $\mathrm{C}$, pantothenic acid, vitamin B6, iron, phosphorus, niacin, thiamin and riboflavin, milligram was used as a unit of measurement, while microgram was used as a unit of measurement for vitamin $\mathrm{D}$, vitamin $\mathrm{K}$, folate, vitamin $\mathrm{B} 12$ and selenium.

${ }^{\dagger}$ The McNemar's test was used when comparing micronutrient deficiency between patients with HF and healthy older adults. An Exact test was used when the number of discordant pairs was less than 10.

¥ The McNemar's test was used.

${ }^{\S}$ Micronutrient deficiency status based on the estimated average requirement.

" Determined using paired $t$-tests for the log-transformed micronutrients.

"Micronutrient deficiency status based on probability formula.

** Micronutrient deficiency status based on $<50 \%$ adequate intake value.

${ }^{\dagger \dagger}$ Determined using Wilcoxon signed-rank tests for the log-transformed micronutrients. 
Table 5. Summary of the micronutrients, including geometric means and their corresponding $95 \%$ confidence intervals after adjusting for 1000 $\mathrm{kcal} / \mathrm{d}$ between age- and sex-matched healthy adults and patients with heart failure groups $(N 102)$

\begin{tabular}{|c|c|c|c|}
\hline \multirow[b]{2}{*}{ Variable } & \multicolumn{2}{|c|}{ Geomean (95 \% Cl) } & \multirow[b]{2}{*}{$P$-value } \\
\hline & Healthy ( $n 51)$ & $\mathrm{HF}(n 51)$ & \\
\hline Calcium & $528(465,600)$ & $459(400,526)$ & $0.162^{\dagger}$ \\
\hline Magnesium & $174(159,192)$ & $152(140,165)$ & $0.037^{\dagger}$ \\
\hline Vitamin D & $4.3(3.3,5.5)$ & $3.2(2.5,4 \cdot 1)$ & $0.142^{\dagger}$ \\
\hline Vitamin E & $9.5(6.7,13.5)$ & $8 \cdot 2(5.5,12)$ & $0.600^{\dagger}$ \\
\hline Zinc & $6.9(5.8,8.2)$ & $7 \cdot 3(6 \cdot 2,8 \cdot 6)$ & $0.634^{\dagger}$ \\
\hline Vitamin C & $74.8(56 \cdot 6,98 \cdot 7)$ & $48.6(35.4,66 \cdot 6)$ & $0.049^{\dagger}$ \\
\hline Vitamin $\mathrm{K}$ & $52 \cdot 2(43.7,62.4)$ & $47.7(38.4,59.1)$ & $0.495^{\dagger}$ \\
\hline Folate & $337(235,484)$ & $262(225,303)$ & $0.219^{\ddagger}$ \\
\hline Vitamin $B_{12}$ & $6.1(3.2,11.6)$ & $4.5(2.7,7.4)$ & $0.566^{\ddagger}$ \\
\hline Pantothenic acid & $4.8(3 \cdot 8,5 \cdot 9)$ & $3.9(3.3,4.6)$ & $0.140^{\dagger}$ \\
\hline Vitamin $B_{6}$ & $1.6(1.3,2)$ & $1 \cdot 2(1.1,1.4)$ & $0 \cdot 130^{\ddagger}$ \\
\hline Selenium & $78.4(50 \cdot 6,121 \cdot 3)$ & $57.5(52.7,62.9)$ & $0.541^{\ddagger}$ \\
\hline Iron & $8.5(7.5,9.7)$ & $9.6(8,11.5)$ & $0.291^{\dagger}$ \\
\hline Phosphorus & $657(618,699)$ & $656(615,700)$ & $0.488^{\ddagger}$ \\
\hline Niacin & $17.9(14 \cdot 3,22 \cdot 5)$ & $14.7(12.5,17 \cdot 3)$ & $0.241^{\ddagger}$ \\
\hline Thiamin & $1.2(1,1.5)$ & $1.1(1,1.2)$ & $0.177^{\ddagger}$ \\
\hline Riboflavin & $1 \cdot 6(1 \cdot 3,2)$ & $1.4(1.3,1 \cdot 6)$ & $0.573^{\ddagger}$ \\
\hline
\end{tabular}

$\mathrm{Cl}$, confidence interval; $\mathrm{HF}$, heart failure.

Dietary micronutrient intakes were calculated as 4-day average.

Geomean was calculated as the result of back transformation of the mean of the logarithms of dietary micronutrient intakes per $1000 \mathrm{kcal} / \mathrm{d}$.

For calcium, magnesium, vitamin E, zinc, vitamin C, pantothenic acid, vitamin B6, iron, phosphorus, niacin, thiamin and riboflavin, milligram was used as a unit of measurement, while microgram was used as a unit of measurement for vitamin $D$, vitamin $\mathrm{K}$, folate, vitamin $\mathrm{B} 12$ and selenium.

${ }^{\dagger}$ Determined using paired $t$-tests for the energy-adjusted log-transformed micronutrients.

${ }^{\ddagger}$ Determined using Wilcoxon signed-rank tests for the energy-adjusted logtransformed micronutrients.

of patients with HF being in the high micronutrient deficiency group was four times higher than similarly aged healthy older adults in the adjusted model (95\% confidence interval [1.06, $15 \cdot 41])$.

\section{Discussion}

The HEI has become a common method of comparing diet quality across multiple populations ${ }^{(20-23)}$. The HEI-2015 was similar between the patients with $\mathrm{HF}$ and healthy older adults, except whole grains. In contrast, when we compared macroand micronutrient intakes, we found lower macronutrient and micronutrient intakes in patients with $\mathrm{HF}$ compared with age- and sex-matched healthy older adults. These significant differences in nutrient intakes diminished when we compared macronutrient intake as percent food energy and micronutrient intake based on $1000 \mathrm{kcal} / \mathrm{d}$ except in the case of magnesium and vitamin $C$. In addition, we found a higher number of micronutrient deficiencies in patients with HF compared with the healthy older adults. Two conclusions are suggested from these data. First, diet quality is an important factor to consider in patients with HF. Second, HF, rather than age, appears to play an important role in diet quality, defined by micronutrient deficiency in patients with HF.

HF often co-exists with lower diet quality, which is associated with increased rehospitalisation and mortality ${ }^{(7,24,25)}$. Wu et al. found an association of vitamin C deficiency with health-related quality of life and cardiac event-free survival ${ }^{(24)}$. Insufficient nutrition with poor health outcomes can also occur in older adults ${ }^{(26,27)}$. The results of our study indicated that older patients with $\mathrm{HF}$ were at higher risk of having micronutrient deficiencies than sex- and age-matched healthy older adults. The potential reasons for lower diet quality in those with HF include polypharmacy, HF symptoms, the impact of depressive symptoms, and dietary restrictions that decrease appetite.

On average, patients with HF take seven prescribed medications per day, excluding over-the-counter or complementary and alternative medications, and the prevalence of polypharmacy is increasing ${ }^{(28-32)}$. The prevalence of excessive polypharmacy in patients with $\mathrm{HF}$ is about 2.5 times higher compared with community-dwelling older individuals ${ }^{(33-35)}$. Cobretti et al. found that $72 \%$ of older patients with $\mathrm{HF}$ were taking more than ten medications, and $40 \%$ were taking sixteen or more medications ${ }^{(36)}$. Polypharmacy could interfere with food consumption due to medication side effects, such as nausea, decreased appetite, dry mouth, and metallic taste ${ }^{(37-40)}$. For example, cardiac and anti-inflammatory medications cause taste dysfunction and are frequently linked to loss of appetite and anorexia ${ }^{(41,42)}$. Additionally, patients with diminished taste acuity may increase their sugar and/or fat intake ${ }^{(43)}$. To avoid the impact of polypharmacy on food intake, clinicians could (1) review medication history and each medication patients are currently taking, including over-the-counter or complementary and alternative medications, to identify medications that change patients' appetites and to prevent possible interactions, (2) prescribe the most appropriate medication that is least likely to change patients' appetites or alter the sense of smell or taste and (3) eliminate unnecessary medications to reduce the impact of polypharmacy on food intake among patients with $\mathrm{HF}^{(44)}$.

HF symptoms might also contribute to lower diet quality. Intestinal oedema that occurs with fluid overload can

Table 6. Association between heart failure status and diet quality using HEl-2015 and micronutrient deficiency in age- and sex-matched older adults ( $N$ 99)

\begin{tabular}{|c|c|c|c|c|}
\hline & \multicolumn{2}{|c|}{ HEI-2015 } & \multicolumn{2}{|c|}{ Micronutrient deficiency } \\
\hline & OR $(95 \% \mathrm{Cl})$ & $P$-value & OR $(95 \% \mathrm{Cl})$ & $P$-value \\
\hline \multicolumn{5}{|c|}{ Heart failure status } \\
\hline Unadjusted $^{\dagger}$ & $2.13(0.92,4.92)$ & 0.079 & $3.43(1.48,7.96)$ & 0.004 \\
\hline Adjusted $^{\ddagger}$ & $0.79(0.19,3.38)$ & 0.751 & $4.04(1.06,15.41)$ & 0.041 \\
\hline
\end{tabular}

OR, odds ratio; $\mathrm{Cl}$, confidence interval.

† Unadjusted model.

${ }^{\ddagger}$ Adjusted model. Conditional logistic regression model was used for the analysis. The HEI-2015 scores were divided into two groups at the median value. The number of dietary micronutrient deficiency was divided into two groups using a cut-off point of $>1$. Marital status (married/cohabitating, single/divorced/separated/widowed), BMl ( $\mathrm{kg} / \mathrm{m}^{2} ;$ continuous), financial status (comfortable, not comfortable) and living arrangements (live alone, live with someone) were controlled in the adjusted model. 
contribute to loss of appetite and decreased food intake ${ }^{(45-47)}$. Andreae et al. found decreased appetite in about one-third of patients with HF; lower functional capacity was associated with lower appetite ${ }^{(48)}$. Persistent shortness of breath can interfere with patients' energy to prepare food, and they may purchase prepared foods that are often higher in fat, salt and sugar components compared with food cooked at home ${ }^{(37,49)}$. Lennie et al. reported fatigue as well as shortness of breath as factors that affect food intake in patients with HF when compared with healthy elders ${ }^{(49)}$. To decrease the negative impact of HF symptoms on diet quality, clinicians could focus on early detection of HF, monitor patients' functional status and HF symptoms, and optimise symptom control.

Depressive symptoms are a major concern in HF. Approximately $20-40 \%$ of patients with HF have depression and about half of them have significant depression ${ }^{(50)}$. The impact of depressive symptoms can result in lower diet quality due to a decrease in appetite or change in patients' food preferences ${ }^{(51-53)}$. Fernstrom et al. reported an increased desire for carbohydrate and fat-rich foods in patients who were having depressive episodes compared with those who were feeling well ${ }^{(52)}$. Andreae et al. found a significant association between higher levels of depressive symptoms and poor appetite in patients with $\mathrm{HF}^{(48)}$. Thus, clinicians should periodically screen depressive symptoms, monitor their effect on change in food preferences and appetite, and intervene to reduce depressive symptoms in patients with HF.

Dietary restrictions might be another factor that lowers diet quality in patients with HF. Lennie et al. found that sodium and other diet restrictions affected food intake in patients with $\mathrm{HF}^{(49)}$. Although healthy elders also perceived sodium restriction to be a substantial barrier that affected food intake ${ }^{(54)}$, the impact of dietary restriction on food intake was greater in patients with HF than healthy elders ${ }^{(49)}$. Comorbidities, such as diabetes, chronic lung disease, ischaemic heart disease and chronic kidney disease, are common in patients with $\mathrm{HF}$ and require additional dietary restrictions, such as carbohydrates, proteins, fats, sodium and fluids, which can affect food intake ${ }^{(55-57)}$. Clinicians should consider referring their patients with multiple dietary restrictions to dieticians to help optimise their diet quality.

Our results in combination with prior research suggest that patients with HF are at risk for decreased food intake that can result in dietary deficiencies. If possible, healthcare providers should recommend patients to increase food intake or if not then encourage them to eat a more nutrient-dense diet, such as vegetables, whole grains and lean protein, and foods prepared with little or no saturated fats, added sugars and sodium $^{(58)}$.

Our study has limitations. Our study was observational, which limits drawing cause and effect conclusions. However, we used a healthy older comparison group and a conditional logistic regression model which confirmed that HF status was associated with having low diet quality. Our study sample was mainly Caucasian. Thus, the results may not be generalisable to other populations with HF. There were differences between groups on variables that can influence food intake because these were not randomised samples. For example, people who eat often with somebody rather than alone consume more food. Thus, we included them in the conditional logistic regression model as covariates to control for their effects on food intake. We found group differences after controlling for these covariates, suggesting that the differences were independent of their influence. However, we could not include all potential confounders due to the limited sample size. Also, there might be unmeasured confounders. Because dietary record data were self-reported, there may be inaccuracies, including under-reporting ${ }^{(59)}$. To reduce inaccuracies, participants were given digital scales with detailed oral instruction by a research assistant, including paper instruction. Food models were also given to participants, so that they could estimate their serving sizes if they went out to eat where they could not use scales. Return demonstration of food measurement and recording food diary were also requested to ensure the accuracy of food diary recordings. Research nurses called participants to review the procedure and answer any questions they had on the first day of the food diary collection. Dietitians carefully reviewed food diaries with participants at the time of their visit to verify food preparation and serving sizes necessary to quantify nutrient analyses. In addition, we collected 4-day food diaries, including 1 weekend day and 3 weekdays, to account for day-to-day variations in food intake.

\section{Conclusions}

Given that the patients with HF and healthy older adults were age-matched, our findings indicate that lower diet quality in patients with $\mathrm{HF}$ was a function of $\mathrm{HF}$ rather than age. HEI-2015 and nutrient density of diet were similar between patients with HF and healthy older adults. However, patients with HF had lower dietary intake compared with healthy older adults.

Importantly, we found that magnesium and vitamin $\mathrm{C}$ remained significantly lower in patients with HF compared with healthy older adults after we controlled for differences in food intake by referencing micronutrient intake per 1000 kcal. This suggests that patients with HF are at particular risk for deficiencies of these micronutrients. To avoid micronutrient deficiency, healthcare providers may need to encourage more nutrient-dense diets for patients with $\mathrm{HF}$ to compensate for decreased intake.

\section{Acknowledgments}

JH.K., D.K.M., M.J.B. and T.A.L. contributed to the research question and the design of the study. GY.O. and JH.K. contributed to the age- and sex-matched data preparation and data analysis. First draft of the manuscript was prepared by JH.K. All authors commented on the manuscript and approved the final manuscript.

This study was supported by RO1 NR 009280 (Lennie, T.A. PI) and P20 NR 010679 (Moser, D.K. PI). The contents of this manuscript are solely the responsibility of the authors and do not necessarily represent the official views of the grant funding agencies.

The authors declare that they have no conflicts of interest. 


\section{References}

1. Virani SS, Alonso A, Benjamin EJ, et al. (2020) Heart disease and stroke statistics-2020 update: a report from the American Heart Association. Circulation 141, e139-e596.

2. Heidenreich PA, Albert NM, Allen LA, et al. (2013) Forecasting the impact of heart failure in the United States: a policy statement from the American Heart Association. Circ Heart Fail 6, 606-619.

3. Gerber Y, Weston SA, Redfield MM, et al. (2015) A contemporary appraisal of the heart failure epidemic in Olmsted County, Minnesota, 2000 to 2010. JAMA Intern Med 175, 996-1004.

4. Yancy CW, Jessup M, Bozkurt B, et al. (2017) 2017 ACC/AHA/ HFSA focused update of the 2013 ACCF/AHA Guideline for the management of heart failure: a report of the American College of Cardiology/American Heart Association Task Force on Clinical Practice Guidelines and the Heart Failure Society of America. Circulation 136, e137-e161.

5. Aggarwal M, Bozkurt B, Panjrath G, et al. (2018) Lifestyle modifications for preventing and treating heart failure. J Am Coll Cardiol 72, 2391-2405.

6. Uysal H, ÖZ Alkan H, EnÇ N, et al. (2020) Assessment of dietary habits in patients with chronic heart failure. J Nurs Res 28, e65.

7. Lennie TA, Andreae C, Rayens MK, et al. (2018) Micronutrient deficiency independently predicts time to event in patients with heart failure. J Am Heart Assoc 7, e007251.

8. Pinto de Souza Fernandes D, Duarte MSL, Pessoa MC, et al. (2017) Evaluation of diet quality of the elderly and associated factors. Arch Gerontol Geriatr 72, 174-180.

9. Bergstralh E \& Kosanke J (2007) Computerized matching of cases to controls using the greedy matching algorithm with a fixed number of controls per case. Controls may be matched to cases using one or more factors (X's). Biomedical Statistics and Informatics Software Packages. http://bioinformaticstools.mayo.edu/research/ gmatch/ (accessed May 2020).

10. USDoHaHSaUSDo Agriculture (2015) 2015-2020 Dietary Guidelines for Americans. Available from: https://health.gov/ our-work/food-nutrition/2015-2020-dietary-guidelines/guidelines/.

11. Guenther PM, Reedy J \& Krebs-Smith SM (2008) Development of the healthy eating index-2005. J Am Diet Assoc 108, 1896-1901.

12. Miller PE, Mitchell DC, Harala PL, et al. (2011) Development and evaluation of a method for calculating the Healthy Eating Index-2005 using the Nutrition Data System for Research. Public Health Nutr 14, 306-313.

13. Nutrition Coordinating Center (2014) NDSR User Manual. http:// www.ncc.umn.edu/products/ndsr-user-manual/ (accessed September 2015).

14. Krebs-Smith SM, Pannucci TE, Subar AF, et al. (2018) Update of the healthy eating index: HEI-2015. J Acad Nutr Diet 118, 15911602.

15. Reedy J, Lerman JL, Krebs-Smith SM, et al. (2018) Evaluation of the Healthy Eating Index-2015. J Acad Nutr Diet 118, 1622-1633.

16. Shan Z, Rehm CD, Rogers G, et al. (2019) Trends in dietary carbohydrate, protein, and fat intake and diet quality among US adults, 1999-2016. JAMA 322, 1178-1187.

17. Institute of Medicine (US) Food and Nutrition Board (2006) Dietary Reference Intakes. The Essential Guide to Nutrient Requirements. Washington, DC: The National Academies Press.

18. Institute of Medicine (US) Food and Nutrition Board (2011) Dietary Reference Intakes for Calcium and Vitamin D. Washington, DC: The National Academies Press.

19. Institute of Medicine (US) Food and Nutrition Board (2000) Dietary Reference Intakes: Applications in Dietary Assessment (2000). Washington, DC: The National Academies Press.

20. Grimstvedt ME, Woolf K, Milliron BJ, et al. (2010) Lower Healthy Eating Index-2005 dietary quality scores in older women with rheumatoid arthritis v. Healthy controls. Public Health Nutr 13, $1170-1177$.
21. Xu B, Houston D, Locher JL, et al. (2012) The association between Healthy Eating Index-2005 scores and disability among older Americans. Age Ageing 41, 365-371.

22. Koksal E, Karacil Ermumcu MS \& Mortas H (2017) Description of the healthy eating indices-based diet quality in Turkish adults: a cross-sectional study. Environ Health Prev Med 22, 1-9.

23. Root MM, Houser SM, Anderson JJ, et al. (2014) Healthy Eating Index 2005 and selected macronutrients are correlated with improved lung function in humans. Nutr Res 34, 277-284.

24. Wu JR, Song EK, Moser DK, et al. (2019) Dietary vitamin C deficiency is associated with health-related quality of life and cardiac eventfree survival in adults with heart failure. J Cardiovasc Nurs 34, 29-35.

25. Song EK, Wu JR, Moser DK, et al. (2018) Vitamin D supplements reduce depressive symptoms and cardiac events in heart failure patients with moderate to severe depressive symptoms. Eur J Cardiovasc Nurs 17, 207-216.

26. Van Bokhorst-de van der Schueren MA, Lonterman-Monasch S, de Vries OJ, et al. (2013) Prevalence and determinants for malnutrition in geriatric outpatients. Clin Nutr 32, 1007-1011.

27. Sahin S, Tasar PT, Simsek H, et al. (2016) Prevalence of anemia and malnutrition and their association in elderly nursing home residents. Aging Clin Exp Res 28, 857-862.

28. Page RL, 2nd, O’Bryant CL, Cheng D, et al. (2016) Drugs that may cause or exacerbate heart failure: A scientific statement from the American Heart Association. Circulation 134, e32-e69.

29. Hopper I, Skiba M, Windebank E, et al. (2016) Polypharmacy in heart failure-is reducing medication safe? Int J Cardiol 214, 529-530.

30. Wong CY, Chaudhry SI, Desai MM, et al. (2011) Trends in comorbidity, disability, and polypharmacy in heart failure. $A m \mathrm{~J}$ Med 124, 136-143.

31. Rich MW (2012) Pharmacotherapy of heart failure in the elderly: adverse events. Heart Fail Rev 17, 589-595.

32. Masoudi FA, Baillie CA, Wang Y, et al. (2005) The complexity and cost of drug regimens of older patients hospitalized with heart failure in the United States, 1998-2001. Arch Intern Med 165, 2069-2076.

33. Kennel PJ, Kneifati-Hayek J, Bryan J, et al. (2019) Prevalence and determinants of Hyperpolypharmacy in adults with heart failure: an observational study from the National Health and Nutrition Examination Survey (NHANES). BMC Cardiovasc Disord 19, 76.

34. Badawy NA, Labeeb SA, Alsamdan MF, et al. (2020) Prevalence and risk of polypharmacy among community-dwelling, elderly Kuwaiti patients. Med Principles Pract 29, 166-173.

35. Morin L, Johnell K, Laroche M-L, et al. (2018) The epidemiology of polypharmacy in older adults: register-based prospective cohort study. Clin Epidemiol 10, 289-298.

36. Cobretti MR, Page RL, 2nd, Linnebur SA, et al. (2017) Medication regimen complexity in ambulatory older adults with heart failure. Clin Interv Aging 12, 679-686.

37. Jyrkkä J, Enlund H, Lavikainen P, et al. (2011) Association of polypharmacy with nutritional status, functional ability and cognitive capacity over a three-year period in an elderly population. Pharmacoepidemiol Drug Saf 20, 514-522.

38. Imoscopi A, Inelmen EM, Sergi G, et al. (2012) Taste loss in the elderly: epidemiology, causes and consequences. Aging Clin Exp Res 24, 570-579.

39. Masnoon N, Shakib S, Kalisch-Ellett L, et al. (2017) What is polypharmacy? A systematic review of definitions. BMC Geriatr 17, 230-230.

40. Heuberger RA \& Caudell K (2011) Polypharmacy and nutritional status in older adults: a cross-sectional study. Drugs Aging 28, 315-323.

41. Pickering G (2004) Frail elderly, nutritional status and drugs. Arch Gerontol Geriatr 38, 174-180.

42. Doty RL, Shah M \& Bromley SM (2008) Drug-induced taste disorders. Drug Saf 31, 199-215.

43. Douglass R \& Heckman G (2010) Drug-related taste disturbance: a contributing factor in geriatric syndromes. Can Fam Physician 56, 1142-1147.

44. Fitzgerald RJ (2009) Medication errors: the importance of an accurate drug history. Br J Clin Pharmacol 67, 671-675. 
45. Sundaram V \& Fang JC (2016) Gastrointestinal and liver issues in heart failure. Circulation 133, 1696-1703.

46. Jacobsson A, Pihl-Lindgren E \& Fridlund B (2001) Malnutrition in patients suffering from chronic heart failure; the nurse's care. Eur J Heart Fail 3, 449-456.

47. Jaarsma T, Abu-Saad HH, Halfens R, et al. (1997) 'Maintaining the balance' nursing care of patients with chronic heart failure. Int $\mathrm{J}$ Nurs Stud 34, 213-221.

48. Andreae C, Strömberg A \& Årestedt K (2016) Prevalence and associated factors for decreased appetite among patients with stable heart failure. J Clin Nurs 25, 1703-1712.

49. Lennie TA, Moser DK, Heo S, et al. (2006) Factors influencing food intake in patients with heart failure: a comparison with healthy elders. J Cardiovasc Nurs 21, 123-129.

50. Mbakwem A, Aina F \& Amadi C (2016) Expert opinion-depression in patients with heart failure: is enough being done? Card Fail Rev 2, $110-112$.

51. Paykel ES (1977) Depression and appetite. J Psychosom Res 21, 401-407.

52. Fernstrom MH, Krowinski RL \& Kupfer DJ (1987) Appetite and food preference in depression: effects of imipramine treatment. Biol Psycbiatry 22, 529-539.

53. Kang J, Moser DK, Biddle MJ, et al. (2020) Inflammatory properties of diet mediate the effect of depressive symptoms on Framingham risk score in men and women: results from the National Health and Nutrition Examination Survey (2007-2014). Nutr Res 74, 78-86.

54. Mattes RD (1984) Salt taste and hypertension: a critical review of the literature. J Chronic Dis 37, 195-208.

55. Lawson CA, Solis-Trapala I, Dahlstrom U, et al. (2018) Comorbidity health pathways in heart failure patients: a sequences-of-regressions analysis using cross-sectional data from 10,575 patients in the Swedish Heart Failure Registry. PLoS Med 15, e1002540.

56. Micha R, Wallace SK \& Mozaffarian D (2010) Red and processed meat consumption and risk of incident coronary heart disease, stroke, and diabetes mellitus: a systematic review and meta-analysis. Circulation 121, 2271-2283.

57. Centers for Disease Control and Prevention (2019) Diabetes and Kidney Disease: What to Eat? https://www.cdc.gov/diabetes/managing/eat-well/what-to-eat.html.

58. American Health Association (2018) How Can I Eat More Nutrient-Dense Foods? https://www.heart.org/en/healthy-living/ healthy-eating/eat-smart/nutrition-basics/how-can-i-eat-morenutrient-dense-foods (accessed June 2021).

59. Bedard D, Shatenstein B \& Nadon S (2004) Underreporting of energy intake from a self-administered food-frequency questionnaire completed by adults in Montreal. Public Health Nutr 7, 675-681. 